\title{
Review
}

\section{Antiviral therapy for human rabies}

\author{
Camila M Appolinario ${ }^{1}$, Alan C Jackson ${ }^{2 *}$ \\ 'Department of Veterinary Hygiene and Public Health, School of Veterinary Medicine and Animal Science, São Paulo State University, \\ Botucatu, São Paulo, Brazil \\ ${ }^{2}$ Departments of Internal Medicine (Neurology) and of Medical Microbiology, University of Manitoba, Winnipeg, MB, Canada \\ *Corresponding author e-mail: ajackson2@hsc.mb.ca
}

\begin{abstract}
Human rabies is virtually always fatal despite numerous attempts at aggressive therapy. Most survivors received one or more doses of rabies vaccine prior to the onset of the disease. The Milwaukee Protocol has proved to be ineffective for rabies and should no longer be used. New approaches are needed and an improved understanding of basic mechanisms responsible for the clinical disease in rabies may prove to be useful for the development of novel therapeutic approaches. Antiviral therapy is thought to be an important component of combination therapy for the management of human rabies, and immunotherapy and neuroprotective therapy should also be strongly considered. There are many important issues for consideration regarding drug delivery to the central
\end{abstract}

nervous system in rabies, which are in part related to the presence of the blood-brain barrier and also the blood-spinal cord barrier. Ribavirin and interferon- $\alpha$ have proved to be disappointing agents for the therapy of rabies. There is insufficient evidence to support the continued use of ketamine or amantadine for the therapy of rabies. Minocycline or corticosteroids should not be used because of concerns about aggravating the disease. A variety of new antiviral agents are under development and evaluation, including favipiravir, RNA interference (for example, small interfering [si]RNAs) and novel targeted approaches, including interference with viral capsid assembly and viral egress.

\section{Introduction}

Although rabies can be very effectively prevented after recognized exposures, the disease remains virtually always fatal despite numerous attempts of aggressive approaches to the management of human disease. Most rabies survivors have received one or more doses of rabies vaccine prior to the onset of the disease [1,2]. Approaches to the therapy of human rabies were recently reviewed, including the failure of the 'Milwaukee Protocol' that should no longer be used because of a lack of efficacy [3]. Current approaches to the therapy of rabies are compromised by limitations on our understanding of basic mechanisms that are responsible for neuronal injury and dysfunction in the disease [4]. In this review, we will focus on the issues and challenges associated with antiviral therapy of rabies. In the future, antiviral therapy of human patients will ideally be combined with other therapies. Both immunotherapy and neuroprotective therapy are clearly areas of considerable interest and these therapies will only be briefly addressed here.

\section{Rabies pathogenesis}

Current knowledge about the pathogenesis of rabies, mostly derived from animal models, has recently been reviewed [4]. Rabies virus is usually transmitted in saliva by an animal bite, although rarely transmission has occurred by inhalation of an aerosol in a laboratory or in a cave containing millions of bats, or iatrogenically by transplantation of tissues (cornea or vascular conduit) or organs. The virus is inoculated in saliva into subcutaneous tissues and/or muscles, and usually remains at the site of entry for weeks or months. Rabies virus binds to nicotinic acetylcholine receptors at the neuromuscular junction (with bites involving muscles) and spreads within peripheral nerves by retrograde fast axonal transport towards the central nervous system (CNS) and subsequently spreads throughout the CNS by fast axonal transport along neuroanatomical connections. Neurons are predominantly infected and histopathological studies show mild inflammatory changes without prominent 
neurodegenerative changes. There is centrifugal spread from the CNS along sensory and autonomic nerves to multiple organs, including the eyes, heart (sometimes associated with myocarditis), adrenal medulla, gastrointestinal tract, salivary glands (important in rabies vectors) and skin. The skin involvement forms the basis of a skin biopsy to demonstrate the presence of either rabies virus RNA or detection of rabies virus antigen around hair follicles using immunofluorescence.

\section{Clinical features of human rabies}

The clinical features of rabies in humans have recently been reviewed [5]. Rabies usually develops weeks or months (rarely a year or more) after a rabies exposure. Prodromal symptoms are non-specific and include malaise, anorexia, headache, fever, anxiety and agitation. The first neurological symptoms are pain, paresthesias or pruritus at the site of the wound that may have already healed, which reflect viral infection and associated inflammation in local sensory (dorsal root or cranial) ganglia. There are two clinical forms of the disease: encephalitic rabies in $80 \%$ and paralytic rabies in $20 \%$. Encephalitic rabies is characterized by hydrophobia, in which on attempts to swallow there are involuntary contractions of the diaphragm and inspiratory muscles lasting 5 to 15 seconds, episodes of generalized arousal or hyperexcitability lasting minutes that are separated by lucid periods and then progressive deterioration in the level of consciousness to coma. Autonomic features, including hypersalivation, piloerection (gooseflesh), cardiac arrhythmias and priapism are common. In paralytic rabies there is weakness usually beginning in the bitten extremity with progression to quadriparesis and facial weakness with sphincter involvement but with minimal sensory involvement. Although the clinical course is usually longer, patients with paralytic rabies also progress to coma. In both clinical forms cardiac and respiratory complications are common when patients are managed aggressively in critical care units and multiple organ failure may develop. Rabies is almost always fatal with only 10 known survivors [2] and all except one patient received one or more doses of rabies vaccine prior to the onset of clinical disease.

\section{Pathway for evaluation of antiviral agents}

The initial evaluation of a potential antiviral agent for rabies virus infection involves testing in cultured cells, particularly by using rabies virus-infected neuronal cells or primary neurons. Once efficacy is demonstrated, then further evaluation should involve a laboratory animal model of experimental rabies. Most models use either a fixed rabies virus strain (for example, challenge virus standard [CVS] or a street [wild-type] rabies virus strain in adult mice [mice or rats] by a natural route of inoculation [intramuscular, footpad or intradermal]). Bat rabies virus strains should be given by more superficial routes (intradermal or subcutaneous) because viral adaptation has occurred for these routes. An approach should be taken that is potentially effective for drug delivery to the CNS (see Issues with drug delivery into the CNS). Ideally, the next step should include evaluation in a more natural model of rabies, such as using a dog rabies virus variant in a dog model using a peripheral route of inoculation. Use of primates with infection by peripheral inoculation of a street rabies virus would also potentially be a desirable approach, because primates are the closest species to humans and are also dead-end hosts for rabies virus infection. One drawback to all animal models is replicating aggressive therapy in humans that would include critical (intensive) care because of the high costs, requirements for subspecialty veterinary expertise and availability of numerous laboratory and imaging investigations. Without critical care of infected animals, the effectiveness of potential therapies may not be fully realized. Funding of these important studies is nearly an insurmountable barrier for a disease that is rare in developed countries.

\section{Issues with drug delivery into the CNS}

Many obstacles must be overcome in order to effectively deliver therapeutic agents to the CNS, which is an important issue for the treatment of diverse neurologi$\mathrm{cal}$ diseases. Consideration must be given to first-pass metabolism on entering the systemic circulation, the uptake of the drug by other non-target body tissues and the blood-brain barrier (BBB) [6] and the blood-spinal cord barrier [7]. Although there are some fundamental differences between the BBB and blood-spinal cord barrier [7], these will not be addressed in this review. The $\mathrm{BBB}$ is composed of endothelial cells with tight junctions sealing intercellular clefts and assisted by pericytes and astrocytic endfeet and their respective basement membranes, which regulate the entry of compounds. Invasion of T-lymphocytes occurs at the postcapillary venules, where there is a perivascular space [8]. The meninges and the choroid plexus are additional physical barriers that protect the CNS. For the therapy of viral infections of the brain, therapeutic agents must be able to cross the BBB. A number of strategies have been developed in order to achieve this goal.

A prodrug is an inactivated drug form that is biologically converted to an active form by chemicals or enzymes in the target tissue, which is a method to alter undesirable physiochemical characteristics of a drug in order to improve its entry into the CNS [6]. A prodrug can receive a polar group and become lipophilic and increase permeability through the BBB or become associated with an 
endogenous carrier such as a neutral amino acid (LAT1) or hexose (GLUT 1) [9]. This strategy allows large proteins or peptides to cross the BBB via an endocytotic process and can also be used for the delivery of small interfering (si)RNAs into the CNS (see RNA interference). There are also biological strategies based on the use of cell-penetrating peptides that can be transported into the CNS; short sequences of amino acids (rich in the positively charged amino acids arginine and lysine) have the ability to pass through lipid bilayers of cell membrane and enter cells [6].

Nanoparticles are another approach. Drugs may be loaded into a nanocarrier and because they are so small nanoparticles can easily pass through BBB capillaries and diffuse into target cells [6]. Nanoparticles can assume a broad range of types such as polymeric, lipid, magnetic and dendritic carriers [10]. While nanocarriers enable efficient passage of therapeutic agents into the CNS, they can also increase the risks of overexposure to drugs and nanomaterials resulting in neurotoxicity [10].

Another very promising non-invasive method is intranasal drug delivery [6]. This method avoids liver metabolism that all compounds are subjected to when administered systemically. The drug may be delivered into the CNS through the olfactory epithelium in the nasal cavity, first going to the olfactory bulb and spreading to the olfactory and trigeminal nerves with distribution to the brain [6]. A variety of factors may interfere with the delivery such as the chemical nature, molecular weight and particle size of the drug, as well as the drug formulation and physiological aspects of the host, including nasal blood flow, the speed of mucociliary clearance and pathological conditions of the nose [11]. The uptake of chemotherapy drugs in the cerebrospinal fluid using intranasal drug delivery in glioblastoma studies was found to be higher than using intravenous administration, showing the major potential of this strategy [12]. An experimental study in rats showed that intranasal therapy with ribavirin effectively bypassed the BBB [13].

Invasive approaches are based on a drug physically gaining access to the CNS by using surgical procedures (for example, intraventricular administration via an Ommaya reservoir), disruption of the BBB or direct injection into a target site. These methods exclude drugs from the systemic circulation and also reduce peripheral side effects as well as maximize the total amount of drug that reaches the target tissue. BBB permeability can be modulated by a transient disruption of vascular integrity that allows macromolecules to enter the CNS. For example, osmotic disruption of the BBB may be achieved using intracarotid injection of mannitol. Ultrasound-mediated drug delivery is a technique that uses small air, lipid or protein-filled bubbles that are injected along with the drug and then are stimulated by ultrasound waves causing a transient and controlled BBB disruption [6]. An important advantage of this method is that there is no need to chemically alter the drug and thus its therapeutic activity is maintained [14].

\section{Agents that are currently available for use}

The goal of antiviral drug therapy in rabies is to inhibit viral replication and reduce viral spread within the CNS and also potentially reduce centrifugal spread from the CNS to multiple extraneural organs. Antiviral therapy is thought to be an essential component of combination therapy for rabies. Ribavirin and interferon (IFN)- $\alpha$ are the main currently available agents with known activity against rabies virus and studies of their efficacy in rabies are limited.

\section{Ribavirin}

Ribavirin (1- $\beta$-D-ribofuranosyl-1,2,4-triazole-3-carboxamide) is a purine analogue and an RNA mutagen that induces mutations by acting as a template for incorporation of cytidine and uridine with equal efficiency [15]. Ribavirin functions as a broad spectrum antiviral agent and it is currently used to treat HCV [16], Lassa fever virus [17] and respiratory syncytial virus [18] infections in humans. Ribavirin has in vitro activity against rabies virus infection [19-21]. Ribavirin also has pro-inflammatory properties and has recently been shown to induce a transient innate immune response in the mouse brain [21]. No efficacy was demonstrated in a study using intracerebral inoculation of ribavirin in street rabies virus-infected mice [22]. Similarly, a recent in vivo study of ribavirin therapy administered orally in experimental rabies in mice using three different street rabies virus strains failed to demonstrate efficacy of ribavirin therapy [21].

One patient was treated with intrathecal $(2 \mathrm{mg} / \mathrm{kg}$ daily via an Ommaya reservoir) and intravenous (loading dose of $2 \mathrm{~g}$ [30 mg/kg], then $1 \mathrm{~g}$ every $6 \mathrm{~h}$ for 4 days [60 mg/kg/day] and finally $0.5 \mathrm{~g}$ every $8 \mathrm{~h}$ thereafter [25 $\mathrm{mg} / \mathrm{kg} /$ day] ) ribavirin for rabies in Thailand and did not survive [23]. A summary of therapy for human rabies at the You-An Infectious Disease Hospital in Beijing, China over a 15 -year period indicated that 16 of 64 patients received intravenous therapy with ribavirin with no beneficial effect on their survival [24]. Another patient in the United States received intravenous therapy with ribavirin beginning in the third week of illness without apparent benefit $[23,25]$. Ribavirin is known to shift the immune response toward a Th1-type inflammatory response [26]. Because of the importance of a Th1/Th2 balanced immune response for clearance of rabies virus infection, there is concern that ribavirin could suppress antibody production that 
is essential for recovery from rabies. In the case of a Canadian rabies patient who received ribavirin and other drugs for therapy of rabies, the patient died and at autopsy there was a high viral burden and extensive neuronal loss in the brain with marked lymphocytic infiltration, which suggested the possibility of a neurological immune reconstitution syndrome that developed followed discontinuation of therapy [27].

Ribavirin was one component of therapy (Milwaukee Protocol) given to a survivor of rabies [28]. Subsequently, there have been numerous failures of the Milwaukee Protocol [3]. Even the most enthusiastic advocate of this failed protocol no longer recommends inclusion of ribavirin for therapy of rabies patients because of lack of efficacy and adverse effects [29].

IFN- $\alpha$

IFNs, especially type I IFN (IFN- $\alpha / \beta)$, are important primary defences against viral infections. They are produced in almost all cells after the recognition of pathogen-associated molecular patterns (PAMPs) by several receptors, including Toll-like receptors (TLR) and cytoplasmic retinoic-acid-inducible gene I (RIG-I), and induce an activation cascade that leads to the production of type I IFNs. Rabies virus triggers an innate immune response after it enters the nervous system, which includes a type I IFN response, and recent work has shown that this response limits rabies virus dissemination in inoculated muscle, slows down spread to the spinal cord and delays mortality in peripherally inoculated mice [30]. Treatment with exogenous IFN has been shown to prevent rabies virus replication in cell culture, especially when therapy is administered before or at the time of the infection $[31,32]$. Treatment with exogenous IFN or IFN-inducers such as polyriboinosinic-polyribocytidylic acid (poly I:C), including PICKCa that is a poly I:C derivative, can partially or completely inhibit rabies virus infection in mouse and rhesus monkey models [33,34]. Efficacy was greater when large doses of each compound were administered before or shortly after viral infection and as close as possible to the site of the viral inoculation.

Combined intramuscular and intrathecal (lumbar) therapy with human leukocyte IFN beginning one day after viral inoculation showed incomplete protection of street rabies virus - infected cynomolgus monkeys, but not when therapy was initiated after the development of clinical disease [35]. Merigan et al. [36] reported on the administration of human leukocyte IFN of three patients with rabies in the United States, two in France and one in Brazil; three were semicomatose at the time therapy was initiated. Both intramuscular (1-20 MU/day for 10-17 days) and intrathecal (0.5-5 MU/day for 10-17 days via Ommaya or Rickham reservoirs) therapy was used. Although there was a 30-10,000-fold greater elevation in serum and cerebrospinal fluid titres of IFN than normally observed in rabies, there was no evidence of any effect on the progression of the neurological disease. Low and perhaps delayed rabies antibody titres were noted in the three patients from the United States, possibly due to an immunosuppressive effect of the therapy. Warrell et al. [23] treated three human rabies patients with IFN- $\alpha$ in Thailand. The patients were given an intravenous loading dose of $50 \mathrm{MU} / \mathrm{m}^{2}$ over six $\mathrm{h}$ and then repeated at $18 \mathrm{~h}$ and given daily as a continuous intravenous infusion. Intrathecal IFN was given by the lumbar route for the first dose and subsequently administered into the lateral ventricle via an Ommaya reservoir with a loading dose of $2 \mathrm{MU} / \mathrm{m}^{2}$ and then repeated after six $\mathrm{h}$ and then daily (for the third patient the dose was halved after the first week). Consistently high concentrations of IFN- $\alpha$ were detected in the serum and cerebrospinal fluid for several days, but there was no apparent effect on clinical progression of the disease. One of the patients developed severe hyperkalemia. Only one of the three patients developed neutralizing anti-rabies virus antibodies prior to death.

\section{Ketamine}

Ketamine is a dissociative anaesthetic and a noncompetitive N-methyl-D-aspartate (NMDA) receptor antagonist. In very high concentrations (1-2 mM) ketamine was shown to inhibit rabies virus genome transcription [37], whereas NMDA receptor activity occurs at $1 \mu \mathrm{M}$ concentrations. After stereotaxic inoculation of a fixed rabies virus strain into the neostriatum of rats, high-dose ketamine $(60 \mathrm{mg} / \mathrm{kg}$ given intraperitoneally every $12 \mathrm{~h}$ ) led to reduced infection in multiple brain regions, including the hippocampus, cerebral cortex and thalamus [37]. However, more recent evidence from studies in primary neuron cultures and in mice does not support this approach [38]. Ketamine was also a component of therapy (Milwaukee Protocol) given to a survivor of rabies [28]. In the case of Canadian rabies patient who received ketamine and other drugs for the therapy of rabies, the patient died and at autopsy there was a high viral burden and extensive neuronal loss in the brain with marked lymphocytic infiltration, which suggested the possibility of a neurological immune reconstitution syndrome that developed followed discontinuation of potentially immunosuppressive drugs [27], including ketamine [39], midazolam [40] and propofol [41]. Hence, there is no real justification for the continued use of ketamine for the treatment of human rabies unless further studies provide evidence of therapeutic efficacy. 


\section{Amantadine}

Amantadine (1-adamantylamine) is a synthetic antiviral agent that can inhibit the replication of viruses in cells and it is also a weak non-competitive NMDA receptor antagonist that accelerates channel closure during channel block [42]. Amantadine has been used for therapy of Parkinson's disease, but currently there is inadequate evidence of efficacy [43]. There are two in vitro studies evaluating amantadine in rabies virus infection. In one study amantadine was found to interfere with rabies virus (CVS) production in CER cells with dose-dependent inhibition ranging from $10 \%$ at $25 \mu \mathrm{g} / \mathrm{ml}$ to $99.9 \%$ at $250 \mu \mathrm{g} / \mathrm{ml}$ [19]. In another study rabies viral antigen synthesis was inhibited in CER cells with amantadine at concentrations of $4-200 \mu \mathrm{M}$ in the media beginning at the time of infection and up to 30 min later [44]. Amantadine did not inhibit viral replication when the drug was preincubated with the cells and removed before viral infection or when amantadine was added to the virus during the attachment step, suggesting that viral attachment and penetration are probably not affected by the drug. It is likely that amantadine impedes viral uncoating. Amantadine failed to show efficacy in mice when inoculated into the site of intramuscular inoculation of street rabies virus at daily intervals (for up to 5 doses) beginning on the day of viral inoculation [22]. Amantadine was one component of therapy (Milwaukee Protocol) given to a rabies survivor of rabies [28], but there is little justification for its use based on the above reports.

\section{Minocycline}

Minocycline is a tetracycline derivative with broad spectrum antimicrobial activity with anti-inflammatory, anti-apoptotic and anti-oxidant properties. Minocycline has also been reported to suppress viral replication in HIV infection [45]. Beneficial effects have been observed in animal models of encephalitis due to neuroadapted Sindbis virus, simian immunodeficiency virus and Japanese encephalitis virus infection, whereas there was a lack of beneficial effects in reovirus infection in mice and in a human clinical trial for therapy of HIV-associated cognitive impairment [46]. In contrast, harmful effects were observed with minocycline therapy in rabies virus infection of neonatal mice [47] and also in a variety of animal models of neurodegenerative diseases $[46,47]$. Hence, empiric use of minocycline is strongly discouraged [46].

\section{Steroids}

Corticosteroids are generally considered contraindicated in the therapy of rabies except in the setting of adrenocortical insufficiency [48]. In mice [49], rats, hamsters and guinea pigs [50] administration of corticosteroids increased the mortality rate and shortened the incubation period. Brain oedema with the associated risk of brain herniation is rare in rabies except under unusual circumstances (for example, intrathecal therapy of rabies with human rabies immune globulin [51]). Because corticosteroids act to close the BBB there is also concern that this therapy may reduce the entry of other therapeutic agents that may be used for therapy of rabies [52]. Roy and Hooper [53] found that administration of steroid hormone dehydroepiandrosterone in silver-haired bat rabies virus-infected PLSJL mice reduced BBB permeability changes and reduced infiltration of immune effectors into the brain, resulting in greater mortality.

\section{New antiviral agents in development}

Molecular strategies to inhibit the replication of RNA viruses and the associated challenges have recently been reviewed [54,55]. Viral enzymes, particularly polymerases, are potential targets of antiviral drugs [56]. Oligonucleotide antiviral therapeutics will also be a future area for development [57]. Aptamers are singlestranded oligonucleotides that bind their targets with high affinity and specificity. Liang et al. [58] showed that two aptamers targeting rabies virus-infected cells protected mice from a lethal dose of street (wild-type) rabies virus.

\section{Favipiravir}

Favipiravir (6-fluoro-3-hydroxy-2-pyrazinecarboxamide), which is also known as T-750, is a pyrazine derivative that is a new broad-spectrum RNA polymerase inhibitor, but does not interfere with cellular DNA and RNA [59]. The antiviral effects of this drug have been studied in vivo and in vitro in several RNA viral infections caused by West Nile virus [60], influenza virus [61], arenaviruses [62] and hantaviruses [63]. Favipiravir has shown efficacy in a mouse model of western equine encephalitis [64] and also appears to avoid the toxicity of ribavirin. The promising results, especially those obtained in clinical phases of the diseases, should encourage researchers to evaluate this therapy in rabies.

\section{RNA interference}

RNA interference (RNAi) is an endogenous mechanism that was first described in the late 1990s leading to post-transcriptional gene silencing. It is present and well conserved in a broad variety of species, including plants and animals. A short nucleotide sequence (about 21-23 nucleotides in length), also known as siRNAs, which is associated with the RNA-induced silencing complex (RISC), recognizes and binds to complementary mRNA, causing its cleavage into smaller fragments and thus inactivating its expression. RNAi mechanisms play an important role in cellular defence against viral infection 
as well as other important cellular functions such as controlling the mobility of transposable genetic elements and regulation of gene expression during animal development [65]. In recent years, the general potential of these mechanisms have stimulated studies of the use of siRNA and microRNA as therapeutic options for a variety of both infectious and non-infectious diseases.

In rabies siRNAs have been evaluated in both in vitro and in vivo studies and usually the sequences are developed against rabies nucleoprotein $(\mathrm{N})$, glycoprotein $(\mathrm{G})$ and/or polymerase (L) genes with delivery by a vector such as an adenovirus [66] or a liposome [67]. In all studies, siRNAs inhibited viral replication at some level, but in most studies cells or mice were infected with the strain (usually a laboratory-adapted strain) on which the siRNA design was based [65-68]. Therapeutic studies in mice with intracerebral delivery of siRNAs using both an adenoviral vector [66] and liposome-mediated delivery [67] showed protection of mice against a lethal peripheral challenge. The efficacy of protection was much higher (also greater reduction of rabies virus multiplication in cells) with siRNAs against the rabies virus $\mathrm{N}$ gene $(67 \%)$ than the L gene (33\%) [66]. The potential of applying this technology may be more limited against wild-type rabies viruses, because there can be a high rate of genetic variation that leads to a mismatching between the viral gene and the designed sequences. Israsena et al. [69] performed studies evaluating single or multiple artificial microRNAs (amiRNAs) targeting the rabies virus nucleocapsid protein gene and inserted into a vector. Neuro 2A cells were infected with a highly pathogenic wild-type virus and treatment was given with single or multiple amiRNAs. Efficacy of single amiRNAs was lower when compared to multiple amiRNAs, which remained highly effective for inhibition of viral replication. This strategy could be useful to overcome the barriers in the use of RNAi in rabies therapy, because most rabies cases are caused by wild-type virus with an unknown genome.

Kumar et al. [70] have developed a method for delivery of siRNAs to the brain using a small peptide (29 amino acids) derived from the rabies virus glycoprotein, which binds to the nicotinic acetylcholine receptor and is exclusively expressed in neuronal cells. A derivative of the rabies virus glycoprotein peptide containing 9 arginine residues (RVG-9R) binds the RNA and delivers it across the BBB after peripheral administration [70]. Protection of mice from fatal flavivirus encephalitis (due to Japanese encephalitis virus and West Nile virus) has been successfully achieved with administration of intracranial siRNAs [71]. Subsequently, Kumar et al. [70] developed an intravenous therapy with siRNA bound to RVG-9R and administered intravenous therapy daily to mice beginning
$4 \mathrm{~h}$ after intraperitoneal inoculation with Japanese encephalitis virus. Mortality decreased from $100 \%$ to $20 \%$. It is likely that this therapy was effective as protection against the development of fatal encephalitis rather than functioning as effective therapy of established encephalitis. Use of RVG for delivery will target all host neurons that bear nicotinic acetylcholine receptors, which will include the brain, spinal cord and peripheral nervous system. This is particularly important because some of the complications of rabies are likely directly related to infection of extraneural organs after centrifugal spread of the virus occurs [5].

\section{Viral PPxY-Host Nedd4 interface for blocking viral egress}

Budding of filoviruses, arenaviruses and rhabdoviruses is facilitated by subversion of host proteins (for example, Nedd4 E3 ubiquitin ligase) by viral PPxY late (L) budding domains expressed within viral matrix proteins [72]. A small molecule hit inhibited the Nedd4PPxY interaction and PPxY-dependent budding and had broad spectrum antiviral activity and exhibited anti-budding activity against five different viruses, including rabies virus.

\section{Host protein-rabies virus protein interactions as antiviral targets}

An unconventional approach to antiviral drug discovery was used to identify small molecules against rabies virus with conceptualization of viral capsid assembly as occurring via a host-catalysed biochemical pathway rather than by self-assembly [73]. Active compounds were identified without knowing the precise protein target. A cell-free small molecule screen was established in order to recreate hypothesized interactions involving newly synthesized capsid proteins as host assembly machine substrates. By these means a set of proteins, including ATP-binding cassette family E1 (ABCE1), which is a host protein previously known to have a role in ribosome recycling [74] and for HIV capsid formation [75], were identified with marked antiviral potency and an excellent therapeutic index in cell culture.

\section{Immunotherapy for prevention and treatment of rabies}

Following a rabies exposure, thorough wound cleansing and both active and passive immunization are necessary for effective post-exposure prophylaxis (PEP). Current guidelines (Centers for Diseases Control and Prevention [76] and World Health Organization [77]) must be closely followed because minor deviations have led to failure of PEP. Active immunization consists of four (recently reduced from five) doses of a cell culture rabies vaccine (for example, purified chick embryo cell vaccine 
or human diploid cell vaccine given intramuscularly in the deltoid muscle on days 0, 3, 7 and 14 [78]). Passive immunization consists of administration of human rabies immune globulin (HRIG; $20 \mathrm{IU} / \mathrm{kg}$ ) with infiltration into and around the wounds with the residual quantity of HRIG given intramuscularly at a site other than where rabies vaccine was administered (for example, gluteal muscles). The development of serum neutralizing anti-rabies virus antibodies, which are directed against the rabies virus glycoprotein on the surface of mature virus particles, is considered the standard correlate of immunity [79] and, accordingly, is used to determine the need for booster doses of vaccine with pre-exposure rabies vaccination. However, the cell-mediated immune response (via T-lymphocytes) is also a very important aspect of the host's response. Activated T-lymphocytes mediate clearance of rabies virus by different mechanisms. Cytotoxic T-lymphocytes can kill cells with viral surface antigens, whereas T-helper cells can elaborate effector molecules (lymphokines) for stimulation of both cytotoxic T-lymphocytes and B-lymphocytes and for the recruitment macrophages [80].

Immune-mediated viral clearance is thought to be necessary for recovery from rabies [81]. A detailed discussion of immunotherapy for rabies is beyond the scope of this review. The usefulness of administration of rabies vaccine in human patients with rabies is uncertain and possibly detrimental. Inactivated rabies vaccines for humans do not elicit a cytotoxic T-cell response that occurs with live attenuated vaccines for animal use, which is thought to be important for viral clearance [81]. Also, the usefulness of administering human rabies immune globulin to a patient with rabies is unknown. Because immunoglobulins to not normally cross an intact BBB [82], there is uncertainty about the extent to which immunoglobulins would gain entry into the CNS and promote viral clearance. Intravenous administration of rabies immune globulin in association with a method of opening the BBB for entry into the CNS may be effective. Immunostimulatory substances (for example, oligodeoxynucleotides) have been shown to be effective adjuvants for rabies vaccines [83] and also may potentially be useful for therapy of rabies.

\section{Neuroprotective therapy}

An improved understanding of basic mechanisms underlying neuronal injury/dysfunction in rabies virus infection may open the door to novel neuroprotective therapies for rabies, which likely do not have 'antiviral' mechanisms of action and, hence, should not be considered antiviral therapy. Rather than addressing viral replication and spread, the focus would be on ameliorating the neuronal injury induced by the viral infection with an improved understanding of the mechanisms involved. The development of neuroprotective therapies has proved to be very challenging with disappointing results for relatively common acute neurological diseases such as ischaemic stroke [84]. As evidence accumulates that rabies virus infection is a mitochondrial disorder [85-87], the door becomes open for the development of therapies to address the mitochondrial dysfunction and oxidative stress. It is expected that approaches to treatment will follow advances in therapies of other mitochondrial disorders; this remains in its infancy. As a neuroprotective approach, Jackson [3] has suggested using therapeutic hypothermia and, in particular, regional hypothermia involving the head and neck using a cooling helmet or intranasal administration of inert coolant that rapidly evaporates after contact with the nasopharynx. Therapeutic hypothermia is used for therapy on patients who remain unconscious after witnessed cardiac arrest due to ventricular fibrillation; body cooling prevents neuronal injury and improves clinical outcomes $[88,89]$. Although it is widely used, uncertainty about the efficacy of therapeutic hypothermia has recently been raised in light of two very recent clinical trials, even though it is currently widely used after cardiac arrest [90]. Hypothermia reduces cerebral metabolism, production of reactive oxygen species, lipid peroxidation and inflammatory responses, which may explain its benefit. Mitochondrial free radical production is thought to be an important target mechanism for therapeutic hypothermia in ischaemia/reperfusion injury [91]. These new neuroprotective therapies need to be fully evaluated in experimental animal models.

\section{Conclusions}

Antiviral therapy is an important component in an effort to develop effective therapy for human rabies. Access to infected neurons in rabies is challenged by the presence of the $\mathrm{BBB}$ and there are multiple potential strategies for drugs to effectively penetrate this barrier. Therapy with ribavirin and IFN- $\alpha$ have proved to be disappointing for rabies and both agents are associated with potential adverse effects of concern and, hence, there is little rationale for the continued use of these agents. Steroids may reduce the entry of other agents into the brain by closing the BBB. Minocycline should not be used empirically for rabies or other viral infections of the nervous system because of potential detrimental effects, which may be anti-inflammatory or occur through other mechanisms [46,47]. There are new antiviral drugs in development, including favipiravir that have broad-spectrum activity. RNAi (for example, siRNAs) may prove to be effective, but the diversity of wild-type rabies virus strains with sequence differences complicates this approach. Finally, novel targeted approaches, including interference with viral capsid 
assembly, viral egress or other steps in the viral life cycle, may prove to have therapeutic efficacy for this ancient disease. Combination therapy for rabies should potentially include antiviral therapy, immunotherapy and neuroprotective therapy. Neuroprotective therapy is an important area for development in the therapy of rabies, particularly as we gain an improved understanding of basic mechanisms involved in the disease.

\section{Disclosure statement}

The authors declare no competing interests.

\section{References}

1. Jackson AC. Therapy of human rabies. In Jackson AC (Editor). Rabies: scientific basis of the disease and its management. Third Edition. Oxford, UK: Elsevier Academic Press 2013; pp. 573-587.

2. Jackson AC. Recovery from rabies: a call to arms. J Neurol Sci 2014; 339:5-7.

3. Jackson AC. Current and future approaches to the therapy of human rabies. Antiviral Res 2013; 99:61-67.

4. Jackson AC, Fu ZF. Pathogenesis. In Jackson AC (Editor). Rabies: scientific basis of the disease and its management. Third Edition. Oxford, UK: Elsevier Academic Press 2013; pp. 299-349.

5. Jackson AC. Human disease. In Jackson AC (Editor). Rabies: scientific basis of the disease and its management. Third Edition. Oxford, UK: Elsevier Academic Press 2013; pp. 269-298.

6. Stockwell J, Abdi N, Lu X, Maheshwari O, Taghibiglou C. Novel central nervous system drug delivery systems. Chem Biol Drug Des 2014; 83:507-520.

7. Bartanusz V, Jezova D, Alajajian B, Digicaylioglu M. The blood-spinal cord barrier: morphology and clinical implications. Ann Neurol 2011; 70:194-206.

8. Bentivoglio M, Kristensson K. Tryps and trips: cell trafficking across the 100-year-old blood-brain barrier. Trends Neurosci 2014; 37:325-333.

9. Anand BS, Dey S, Mitra AK. Current prodrug strategies via membrane transporters/receptors. Expert Opin Biol Ther 2002; 2:607-620.

10. Wong HL, Wu XY, Bendayan R. Nanotechnological advances for the delivery of CNS therapeutics. Adv Drug Deliv Rev 2012; 64:686-700.

11. Vyas TK, Tiwari SB, Amiji MM. Formulation and physiological factors influencing CNS delivery upon intranasal administration. Crit Rev Ther Drug Carrier Syst $2006 ; 23: 319-347$.

12. van Woensel M, Wauthoz N, Rosiere R, et al. Formulations for intranasal delivery of pharmacological agents to combat brain disease: a new opportunity to tackle GBM? Cancers (Basel) 2013; 5:1020-1048.

13. Colombo G, Lorenzini L, Zironi E, et al. Brain distribution of ribavirin after intranasal administration. Antiviral Res 2011; 92:408-414.

14. Tsutsui JM, Xie F, Porter RT. The use of microbubbles to target drug delivery. Cardiovasc Ultrasound 2004; 2:23.

15. Crotty S, Maag D, Arnold JJ, et al. The broad-spectrum antiviral ribonucleoside ribavirin is an RNA virus mutagen. Nat Med 2000; 6:1375-1379.

16. Martin P, Jensen DM. Ribavirin in the treatment of chronic hepatitis C. J Gastroenterol Hepatol 2008; 23:844-855.

17. McCormick JB, King IJ, Webb PA, et al. Lassa fever. Effective therapy with ribavirin. N Engl J Med 1986; 314:20-26.
18. Weisman LE. Respiratory syncytial virus (RSV) prevention and treatment: past, present, and future. Cardiovasc Hematol Agents Med Chem 2009; 7:223-233.

19. Bussereau F, Chermann JC, De Clercq E, Hannoun C. Search for compounds which have an inhibitory effect on rhabdovirus multiplication in vitro. Annales de l'Institut Pasteur/Virologie 1983; 134:127-134.

20. Bussereau F, Ermine A. Effects of heteropolyanions and nucleoside analogues on rabies virus: in vitro study of syntheses and viral production. Annales de l'Institut Pasteur/Virologie 1983; 134:487-506.

21. Appolinario CM, Prehaud C, Allendorf SD, et al. Ribavirin has an in vitro antiviral effect in rabies virus infected neuronal cells but fails to provide benefit in experimental rabies in mice. J Virol Antivir Res 2013; doi: 10.4172/2324 8955.1000111.

22. Bussereau F, Picard M, Blancou J, Sureau P. Treatment of rabies in mice and foxes with antiviral compounds. Acto Virol 1988; 32:33-49.

23. Warrell MJ, White NJ, Looareesuwan S, et al. Failure of interferon alfa and tribavirin in rabies encephalitis. $B M J$ 1989; 299:830-833.

24. Kureishi A, Xu LZ, Wu H, Stiver HG. Rabies in China: recommendations for control. Bull World Health Organ 1992; 70:443-450.

25. Swanson D, Feigin R, Tanney L, et al. Human rabies - Texas. MMWR Morb Mortal Wkly Rep 1984; 33:469-470.

26. Powers CN, Peavy DL, Knight V. Selective inhibition of functional lymphocyte subpopulations by ribavirin. Antimicrob Agents Chemother 1982; 22:108-114.

27. Reinke SN, Resch L, Maingut F, et al. Metagenomic and metabolomic characterization of rabies encephalitis: new insights into the treatment of an ancient disease. J Infect Dis 2013; 207:1451-1456.

28. Willoughby RE, Jr., Tieves KS, Hoffman GM, et al. Survival after treatment of rabies with induction of coma. $N$ Engl J Med 2005; 352:2508-2514.

29. Willoughby RE, Jr. Are we getting closer to the treatment of rabies? Future Virology 2009; 4:563-570.

30. Chopy D, Detje CN, Lafage M, Kalinke U, Lafon M. The type I interferon response bridles rabies virus infection and reduces pathogenicity. J Neurovirol 2011; 17:353-367.

31. Dacheux L, Delmas O, Bourhy H. Human rabies encephalitis prevention and treatment: progress since Pasteur's discovery. Infect Disord Drug Targets 2011; 11:251-299.

32. Niu X, Tang L, Tseggai T, Guo Y, Fu ZF. Wild-type rabies virus phosphoprotein is associated with viral sensitivity to type I interferon treatment. Arch Virol 2013; 158:2297-2305.

33. Baer GM, Shaddock JH, Moore SA, Yager PA, Baron SS, Levy HB. Successful prophylaxis against rabies in mice and rhesus monkeys: the interferon system and vaccine. I Infect Dis 1977; 136:286-291.

34. Harmon MW, Janis B. Therapy of murine rabies after exposure: efficacy of polyriboinosinic-polyribocytidylic acid alone and in combination with three rabies vaccines. J Infect Dis 1975; 132:241-249.

35. Weinmann E, Majer M, Hilfenhaus J. Intramuscular and/or intralumbar postexposure treatment of rabies virus-infected cynomolgus monkeys with human interferon. Infect Immun $1979 ; 24: 24-31$.

36. Merigan TC, Baer GM, Winkler WG, et al. Collaborative Group. Human leukocyte interferon administration to patients with symptomatic and suspected rabies. Ann Neurol 1984; 16:82-87.

37. Lockhart BP, Tsiang H, Ceccaldi PE, Guillemer S. Ketaminemediated inhibition of rabies virus infection in vitro and in rat brain. Antivir Chem Chemother 1991; 2:9-15.

38. Weli SC, Scott CA, Ward CA, Jackson AC. Rabies virus infection of primary neuronal cultures and adult mice: failure to demonstrate evidence of excitotoxicity. J Virol 2006; 80:10270-10273. 
39. Wilson RD, Priano LL, Traber DL, Sakai H, Daniels JC, Ritzmann SE. An investigation of possible immunosuppression from ketamine and 100 percent oxygen in normal children. Anesth Analg 1971; 50:464-470.

40. Freire-Garabal M, Belmonte A, Balboa JL, Nunez MJ. Effects of midazolam on T-cell immunosuppressive response to surgical stress in mice. Pharmacol Biochem Behav 1992; 43:85-89.

41. Galley HF, Dubbels AM, Webster NR. The effect of midazolam and propofol on interleukin-8 from human polymorphonuclear leukocytes. Anesth Analg 1998; 86:1289-1293.

42. Blanpied TA, Clarke RJ, Johnson JW. Amantadine inhibits NMDA receptors by accelerating channel closure during channel block. J Neurosci 2005; 25:3312-3322.

43. Crosby N, Deane KH, Clarke CE. Amantadine in Parkinson's disease. Cochrane Database Syst Rev 2003; CD003468.

44. Superti F, Seganti L, Pana A, Orsi N. Effect of amantadine on rhabdovirus infection. Drugs Exp Clin Res 1985; 11:69-74.

45. Zink MC, Uhrlaub J, DeWitt J, et al. Neuroprotective and anti-human immunodeficiency virus activity of minocycline. JAMA 2005; 293:2003-2011.

46. Jackson AC. Is minocycline useful for therapy of acute viral encephalitis? Antiviral Res 2012; 95:242-244.

47. Jackson AC, Scott CA, Owen J, Weli SC, Rossiter JP. Therapy with minocycline aggravates experimental rabies in mice. J Virol 2007; 81:6248-6253.

48. Jackson AC, Warrell MJ, Rupprecht CE, et al. Management of rabies in humans. Clin Infect Dis 2003; 36:60-63.

49. Enright JB, Franti CE, Frye FL, Behymer DE. The effects of corticosteroids on rabies in mice. Can J Microbiol 1970; 16:667-675.

50. Enright JB, Goggin JE, Frye FL, Franti CE, Behymer DE. Effects of corticosteroids on rabies virus infections in various animal species. J Am Vet Med Assoc 1970; 156:765-769.

51. Basgoz N, Frosch MP. Case records of the Massachusetts General Hospital: a 32-year-old woman with pharyngeal spasms and paresthesias after a dog bite. N Engl J Med 1998; 339:105-112.

52. Neuwelt EA, Barnett PA, Bigner DD, Frenkel EP. Effects of adrenal cortical steroids and osmotic blood-brain barrier opening on methotrexate delivery to gliomas in the rodent: the factor of the blood-brain barrier. Proc Natl Acad Sci U S A 1982; 79:4420-4423.

53. Roy, A, Hooper DC. Lethal silver-haired bat rabies virus infection can be prevented by opening the blood-brain barrier. J Virol 2007; 81:7993-7998.

54. Bray M. Highly pathogenic RNA viral infections: challenges for antiviral research. Antiviral Res 2008; 78:1-8.

55. Leyssen P, De Clercq E, Neyts J. Molecular strategies to inhibit the replication of RNA viruses. Antiviral Res 2008; 78:9-25.

56. Öberg B. Rational design of polymerase inhibitors as antiviral drugs. Antiviral Res 2006; 71:90-95.

57. Spurgers KB, Sharkey CM, Warfield KL, Bavari S. Oligonucleotide antiviral therapeutics: antisense and RNA interference for highly pathogenic RNA viruses. Antiviral Res 2008; 78:26-36.

58. Liang HR, Hu GQ, Li L, Gao YW, Yang ST, Xia XZ. Aptamers targeting rabies virus-infected cells inhibit street rabies virus in vivo. Int Immunopharmacol 2014; 21:432-438.

59. Furuta Y, Takahashi K, Shiraki K, et al. T-705 (favipiravir) and related compounds: novel broad-spectrum inhibitors of RNA viral infections. Antiviral Res 2009; 82:95-102.

60. Morrey JD, Taro BS, Siddharthan V, et al. Efficacy of orally administered T-705 pyrazine analog on lethal West Nile virus infection in rodents. Antiviral Res 2008; 80:377-379.

61. Kiso M, Takahashi K, Sakai-Tagawa Y, et al. T-705 (favipiravir) activity against lethal H5N1 influenza A viruses. Proc Natl Acad Sci U S A 2010; 107:882-887.
62. Mendenhall M, Russell A, Smee DF, et al. Effective oral favipiravir (T-705) therapy initiated after the onset of clinical disease in a model of arenavirus hemorrhagic fever. PLoS Negl Trop Dis 2011; 5:e1342.

63. Buys KK, Jung KH, Smee DF, Furuta Y, Gowen BB. Maporal virus as a surrogate for pathogenic New World hantaviruses and its inhibition by favipiravir. Antivir Chem Chemother 2011; 21:193-200.

64. Julander JG, Smee DF, Morrey JD, Furuta Y. Effect of T-705 treatment on western equine encephalitis in a mouse model. Antiviral Res 2009; 82:169-171.

65. Meshram CD, Singh NK, Sonwane AA, et al. Evaluation of single and dual siRNAs targeting rabies virus glycoprotein and nucleoprotein genes for inhibition of virus multiplication in vitro. Arch Virol 2013; 158:2323-2332.

66. Gupta PK, Sonwane AA, Singh NK, et al. Intracerebral delivery of small interfering RNAs (siRNAs) using adenoviral vector protects mice against lethal peripheral rabies challenge. Virus Res 2012; 163:11-18.

67. Yang YJ, Zhao PS, Zhang T, et al. Small interfering RNAs targeting the rabies virus nucleoprotein gene. Virus Res 2012; 169:169-174.

68. Brandão PE, Castilho JG, Fahl W, et al. Short-interfering RNAs as antivirals against rabies. Braz J Infect Dis 2007 ; 11:224-225.

69. Israsena N, Supavonwong P, Ratanasetyuth N, Khawplod P, Hemachudha T. Inhibition of rabies virus replication by multiple artificial microRNAs. Antiviral Res 2009; 84:76-83.

70. Kumar P, Wu H, McBride JL, et al. Transvascular delivery of small interfering RNA to the central nervous system. Nature 2007; 448:39-43.

71. Kumar P, Lee SK, Shankar P, Manjunath N. A single siRNA suppresses fatal encephalitis induced by two different flaviviruses. PLoS Med 2006; 3:e96.

72. Han Z, Lu J, Liu Y, et al. Small molecule probes targeting the viral PPxY-host Nedd4 interface block egress of a broad range of RNA viruses. J Virol 2014; 88:7294-7306.

73. Lingappa UF, Wu X, Macieik A, et al. Host-rabies virus protein-protein interactions as druggable antiviral targets. Proc Natl Acad Sci U S A 2013; 110:E861-E868.

74. Becker T, Franckenberg S, Wickles S, et al. Structural basis of highly conserved ribosome recycling in eukaryotes and archaea. Nature 2012; 482:501-506.

75. Zimmerman C, Klein KC, Kiser PK, et al. Identification of a host protein essential for assembly of immature HIV-1 capsids. Nature 2002; 415:88-92.

76. Manning SE, Rupprecht CE, Fishbein D, et al. Human rabies prevention--United States, 2008: recommendations of the Advisory Committee on Immunization Practices. MMWR Recomm Rep 2008; 57:1-28.

77. World Health Organization. WHO expert consultation on rabies: second report (WHO technical report series; no. 982). Geneva: World Health Organization 2013.

78. Rupprecht CE, Briggs D, Brown CM, et al. Use of a reduced (4-dose) vaccine schedule for postexposure prophylaxis to prevent human rabies: recommendations of the Advisory Committee on Immunization Practices. MMWR Recomm Rep 2010; 59:1-9.

79. Hicks DJ, Fooks AR, Johnson N. Developments in rabies vaccines. Clin Exp Immunol 2012; 169:199-204.

80. Wunner WH. Rabies viruses - pathogenesis and immunity. In Wagner RR (Editor). The rhabdoviruses. New York: Plenum Press 1987; pp. 361-426.

81. Lafon M. Immunology. In Jackson AC (Editor). Rabies: scientific basis of the disease and its management. Third Edition. Oxford, UK: Elsevier Academic Press 2013; pp. 387-408.

82. Miller DW. Immunobiology of the blood-brain barrier. J Neurovirol 1999; 5:570-578. 
83. Montaner AD, De Nichilo A, Rodriguez JM, et al. IMT504: a new and potent adjuvant for rabies vaccines permitting significant dose sparing. World Journal of Vaccines 2012; 2:182-188

84. Sutherland BA, Minnerup J, Balami JS, Arba F, Buchan AM, Kleinschnitz C. Neuroprotection for ischaemic stroke: translation from the bench to the bedside. Int J Stroke 2012; $7: 407-418$

85. Jackson AC, Kammouni W, Zherebitskaya E, Fernyhough P. Role of oxidative stress in rabies virus infection of adult mouse dorsal root ganglion neurons. J Virol 2010; 84:4697-4705.

86. Alandijany T, Kammouni W, Roy Chowdhury SK, Fernyhough P, Jackson AC. Mitochondrial dysfunction in rabies virus infection of neurons. J Neurovirol 2013; 19:537-549.

87. Jackson AC, Kammouni W, Wood H, et al. Role of the rabies virus phosphoprotein in the induction of mitochondrial dysfunction in rabies virus infection. 16th International Congress on Infectious Diseases. 5 April 2014, Cape Town, South Africa. Abstract 64.009.
88. Bernard SA, Gray TW, Buist MD, et al. Treatment of comatose survivors of out-of-hospital cardiac arrest with induced hypothermia. N Engl J Med 2002; 346:557-563.

89. The Hypothermia After Cardiac Arrest Study Group. Mild therapeutic hypothermia to improve the neurologic outcome after cardiac arrest. N Engl J Med 2002; 346:549-556.

90. Little NE, Feldman EL. Therapeutic hypothermia after cardiac arrest without return of consciousness: skating on thin ice. JAMA Neurol 2014; 71:823-824.

91. Lampe JW, Becker LB. State of the art in therapeutic hypothermia. Annu Rev Med 2011; 62:79-93. 